\title{
The Effect of Metacognition on Educational Performance and Self-Directed Learning in Sixth Grade Female Students of Shiraz Zone Two
}

Zahra Gholamshahian1

\author{
Ahmadreza Aojinejad2* \\ ${ }^{1}$ Master of Curriculum, Marvdasht Branch, Islamic Azad University, Marvdasht, Iran \\ ${ }^{2}$ Department of Education, Marvdasht Branch, Islamic Azad University, Marvdasht, Iran \\ *Corresponding Author Email: aoji62@yahoo.com
}

Doi:10.5901/mjss.2016.v7n2s2p49

\section{Abstract}

The aim of this study was the effect ofmetacognition, self-directed learning and education performance of sixthgrade girls'zone 2 Shiraz. The method of this study is semi-experimental with pretest and post-test procedure for both group (control group \&experimental group).3937 sixthgrade female student population Zone 2 Shiraz were chosen as sample society,that two groups(each $n=30$ )as amulti-stagecluster sampling in two experimental group and the control group were selected. The instrument was usedin this study, a questionnaire EPT Pham and Taylor to measure the education performance, and Fisher questionnaire to measureself-directed learning. And to analyze the data, descriptive statistics, such as mean, standard deviation, abundance,percent and inferential statistics like $t$ independent were used. The results showed that after training metacognition to the experimental group, we conclude that the rate of creativity and education performance and self-directed learning,the experimental group is morethan the control group.And metacognition training on education performanceand selfdirected learning of studentshas been effected.

Keywords: Metacognition, Educational performance, Self-directed Learning, Femel Students, Shiraz Zone Two

\section{Introduction}

Metacognition is thinking about thinking. The idea that learners think about their thinking dates back to the time of Plato and Aristotle, but metacognition was first entered in developmental psychology by John Flavellin 1967. (Niyaz Azari, 2003)

In fact, in the educational systems in advanced countries, the curriculum development, teaching methods design and developing learning activities are tried to be based on metacognition theory. However, it is almost a decade that the application of metacognition in teaching is being consideredin Iran. In order to understand why developing metacognitive skills is of significance, the process which supervise the cognitive activities and direct them must be studied thoroughly. These skills are effective assessing the problem, learning strategies for solving them, assessing the effectiveness of chosen strategies and changing strategies in order to improve metacognitive learning. (Kadivar, 2008)

Teaching metacognitive strategies leads to improving comprehension and other cognitive actions of the individual. Teaching these strategies leads the individual to supervise all the actions involved in a cognitive action from beginning to the end and guide their learning stream so that their mental processes efficiency increases relative to the available time and resources. Such teachings are useful tools for extending learning to other local and temporal situations. (Kareshki, 2002)

\section{Developing Self-Directed Learning}

The concept of self-directed learning is derived from adults' teaching. Due to the advantages related to the outcomes of self-directed learning, educational and organizational environments seriously emphasize their impotence and its value as a necessary skill for teaching and work in the twenty-first century has been considered. According toFisher, King andTague (2001), self-directed learning inNoleswork is defined as a process in which individuals engage in identifying their learning needs, determining their learning goals, identifying sources and materials needed for learning, selecting and implementing proper strategies and evaluating the learning outcomes with or without other individuals help and take the initiative. Flavell(1981). A couple of aspects should be considered in this definition: First, self-directedlearning as a 
learning process or method and second, taking responsibility which is both a required component and a self-directed learning outcome. From the prospect of experts in adult education, self-directed learning includes three aspects: motivation, metacognition and self-regulation. Individuals with higher levels of self-directed learning are active learners who have a higher tendency towards learning, use problem-solving skills, have required capabilities for engaging in independent learning activities, and autonomously manage their learning. (Musavi, 2013)

In a study under the title of: Individuals' Metacognitive Capabilities are in Relation with Their Creative Thinking, Guilford (1975) claimed that children have identified the nature of work intellectual resources, so that they can control them. Davidson (1991) expressed that helping children for metacognitive understanding of creativity is of significance. Increasing understanding of creativity leads to awareness about creativity, motivating individuals in finding ideas and creative products. Martindale (1995) claimed that a thought is creative which leads to innovative thinking, solution and insight, and that requires interactive components and processes.

Studies of Pintrich (1999) suggest that teaching metacognitive strategies has a huge impact on extending and application of teachings in natural environments. Exercising metacognitive strategies teaches students to identify variables related to problem-solving, organize the problem solution streams perfectly and use specific cognitive skills for doing the homework effectively. (Grow, 1991) Research results from Linda \& Pinkleyey (2006) indicated that, metacognitive skills are used in coping process for problem-solving and by using effecting problem-oriented coping styles, the individual uses cognitive skills for solving problem, and based on this, problem coping methods are studied directly and by finding proper solutions for the problem, psychological satisfaction is usually reached. (Jamalinejad, 2013)

\section{Research Methods}

The objectives of this research include studying the impact of metacognitive teachings on educational performance and the impact of metacognitive teachings on self-directed learning among sixth grade female students of Shiraz district two. The research is a quasi-experimental stud with pretest and posttest for both experiment and control groups and it tries to study the impact of metacognitive teachings effectiveness in educational performance and self-directed learning in students. The independent variable in this research was metacognitive teaching which was carried out on experiment group and the dependent variable were educational performance and self-directed learning which were measured and analyzed in both groups (experiment and control) before and after conducting the experiment. The statistical population included all sixth grade students of primary schools in Shiraz during 2014-2015 school year which included 3,937 students, according to Shiraz Department of Education Statistics and Information Unit. The statistical sample were chosen through multistage cluster sampling, so that among four districts of Shiraz Department of Education, one district and among all schools for girls in this district, one school and from this school, 2 sixth grade classes were randomly chosen. In total, 60 students were randomly chosen and among which, 30 students were in control group and 30 students were in experiment group. In this research, descriptive statistics was used for analyzing data and frequency and tables and diagrams. Inferential statistics was used to study the impact of independent variable on dependent variable and SPSS software was used to analyze the data. In descriptive data par, mean and standard deviation of variables and in inferential statistics the study hypotheses were tested by statistical methods of comparing variances and T-test of independent groups.

\section{Research Tools}

\subsection{GerdanShekan Metacognitive Teaching Pack}

First Session: In the first session, after introducing themselves and getting familiar with the course teacher, students were briefly familiarized with the concept of learning, types of memory and their structures and reasons of forgetfulness. Subsequently, the repetition and review strategyfor simple subjects was taught using various examples and slide show presentation through Microsoft PowerPoint. It should be mentioned that motivation was tried to be formed among the students.

Second Session: In this session, repetition strategy for complex subjects was taught. Subsequently, keyword, acronym, mental imagery, using intermediators and location methods were taught. Students were asked to mention some examples for each of these strategies.

Third Session: In this session, expansion strategies for complex subjects such as notetaking, summarizing, and reciting in own language were taught. Each student would open a chapter of the book randomly they were required to summarize a paragraph. Accordingly, other strategies were practiced by the students. 
Fourth Session: In this session, the relations explanation, interpretation and analysis, using taught information for problem solving, and comparison were taught in the form of previous sessions. Ultimately, the students were assigned some homework for the next session.

Fifth Session: In this session, the organization strategy, including organizing new information based on familiar categories, proving the table of contents, transforming the subject text to map and drawing tree design and preparing diagrams, conceptual map and conceptual pattern were taught in this session. To teach the conceptual map, some examples were introduced from history and sciences books. At the end of the fifth session, the cognitive strategies were summarized.

Sixth Session: The students were introduced to planning strategies from the subset of metacognitive strategies, including study objective, predicting needed time to study, determining studying speed and choosing cognitive strategies.

Seventh Session: Supervision and evaluation strategies from subset of metacognitive strategies including evaluating improvements, supervising the concentration and posing questions during studying time were taught. The main objective of using these strategies is integrative understanding of self-improvement and monitoring and directing it.

Eighth Session: In this session, regulating strategies which include sustainable metacognitive adaptation and improvements which are carried out by the learner in coping with the feedbacks related to errors, were taught. Both groups were tested through creativity, improvement motivation and educational self-concept post-test, after the final session.Seif (2001).

\section{Measuring Tools}

\subsection{Educational Performance Test}

This questionnaire is an adapted questionnaire from Oliveira \& Simoes (2006) research which was built for Iranian society and validated by Kareshky (2002). Its reliability was measured to be $91 \%$ and its content validity was approved by testing the scale statements by several psychology and psychometric experts.

\subsection{Fisher Self-Directed Learning Questionnaire}

Self-directed learning questionnaire includes 52 items. However, in several researches in Iran, the normalized 40-itemed form of the questionnaire has been used.

\section{Analysis Result}

Initially, in order to test this hypothesis, ANOVA was supposed to be used. Hence, the assumptions of using ANOVA should be studied. The first assumption, homogeneity of variances of groups scores:

To achieve this, Levene's test was used. F static value in posttest which was equal to 19.009 with degrees of freedom of 1 and 58 , was significant at 0.001 level $(p<0.05)$. Hence, it could be concluded that variances of groups are homogenous and T-test of independent groups should be used, inevitably.

Table 1. Comparing the Educational Performance between Experiment and Control Groups in Posttest

\begin{tabular}{|l|c|c|c|c|c|c|}
\hline Group & Number of Members & Mean & Standard Deviation & T Value & Degree of Freedom & Significance Level \\
\hline Experiment & 30 & $151 / 46$ & $11 / 17$ & $2 / 05$ & 58 & $0 / 04$ \\
\hline Control & 30 & $147 / 16$ & $2 / 53$ & & & \\
\hline
\end{tabular}

As it could be observed from the above table, $T$ is equal to 2.05 which is significant with degree of freedom of 58 at 0.04 $(p<0.05)$. Hence, it could be concluded that there is a significant difference between the experiment and control group in students' educational performance and considering the means, it becomes clear that despite the control group mean being higher than the experiment group in the pretest, the educational performance in experiment group is higher than the control group in the posttest and this shows the significant impact of teaching metacognition on students' educational performance.

Initially, in order to test this hypothesis, ANOVA as supposed to be used. Hence, the assumptions of using ANOVA should be studied. F static value in posttest which was equal to 12.08 with degrees of freedom of 1 and 58 , was significant at 0.001 level $(p<0.05)$. Hence, it could be concluded that variances of groups are homogenous and T-test of independent groups should be used, inevitably. 
Table 2. Comparing the Self-Regulated Learning Rate between Experiment and Control Groups in Posttest

\begin{tabular}{|l|c|c|c|c|c|c|}
\hline Group & Number of Members & Mean & Standard Deviation & T Value & Degree of Freedom & Significance Level \\
\hline Experiment & 30 & $161 / 73$ & $15 / 8$ & $6 / 61$ & 58 & $0 / 001$ \\
\hline Control & 30 & $141 / 53$ & $5 / 5$ & & & \\
\hline
\end{tabular}

As it could be observed from the above table, $T$ is equal to 6.61 which is significant with degree of freedom of 58 at 0.001 $(p<0.05)$. Hence, it could be concluded that there is a significant difference between the experiment and control group in students' self-regulated learning and considering the means, it becomes clear that, the self-regulated learning in experiment group is higher than the control group in the posttest and this shows the significant impact of teaching metacognition on students' self-regulated learning.

\section{Discussion and Conclusion}

Considering Table 1, it is concluded that there is a significant difference found between educational performance between experiment and control groups. Also, it is observed that educational performance of students who have undergone metacognitive teachings is higher than the educational performance of students who have not undergone metacognitive teachings and the author hypothesis is approved.

In explaining this result, it could be claimed that teaching metacognitive strategies has led students to trust their own capabilities and have a positive reaction towards tests anxiety and worrisome and organize their educational activities based on a specific and executable program using the time in order to do their assignments and their motivation and willingness towards carrying out activities and continuous efforts to finish that activity increases. Teaching metacognitive leads to increasing the students' educational performance, effectively. Failure in active memory and metacognition in children could highly predict their educational performance in school, since metacognitive skills are internal processes which students use for learning, control and supervise, during learning assignments. It seems that students master a set of skills for mastering their assignments. These skills have psychological impacts and they are retrieved through experiencing, teaching and learning. Some students use these skills automatically. Gordanshekan (2011). However, some students are not capable of using these skills and face problems during learning and they are required to undergo some teachings.

Considering Table 2, it could be concluded that there is a significant difference between control and experiment groups in self-directed learning. Self-directed learning rate in students who underwent metacognitive teachings is higher than the students who didn't undergo such teachings and the research hypothesis is approved. Hence, it could be concluded that metacognitive teachings have had a considerable impact on educational performance and creativity and self-directed learning among female sixth grade students of primary schools.

In explaining this result, it could be expressed that metacognitive teaching pack increases the total rate of selfdirection in learning and also its subscales, including awareness, learning strategies, leaning activities, interpersonal skills and evaluations. By utilizing metacognitive teachings, students can learn to think about their own thought processes and become aware of those processes and use special methods during problem solving. Through this, the learning becomes more accurate, complete and stable and leads to improve in the performance of comprehension and other cognitive action of the individual and leads the individual to monitor all actions involved in a cognitive activity from beginning to the end and guide their learning stream so that their metal processes increase comparing to the available time and resources. Such teachings are useful tools for extending learning to other local and temporal situations. Also, teaching metacognition improves the creativity in children and their tendency towards performing creative tasks. Also, metacognitive teachings increase students' self-efficacy, mediation on the goal, focusing on the goal, intrinsic motivation, problem solving skills and self-evaluation. Self-direction in learning is a movement towards self-actualization. Responsibly taking in individuals and being independent in them in learning process are considered to main elements in learning. Forming and training self-directed learning skills have turned to one of the educational goals during the last few decades, so that the number of researches and studies related to self-directed learning has globally increased. Self-directed learners are active and self-motivated individuals who take the initiatives, increased of passive waiting for reactive learning. Their learning is goal-oriented and meaningful and considering the high motivation in them, their learning is more stable and persistence. These individuals are more accountable in their lives and benefit from self-regulating process in learning. Self-directed learners are responsible for their own learning processes. These individuals retain the required skills for accessing and processing information they need for a specific goal. Bardideh,\& Latifi(2004). Today, various teaching systems in world advanced countries try to train humans in a self-directed paradigm. Transforming 
learners to self-directed learners leads them to determine their own needs and learning goals, relative to the existing knowledge.

\section{References}

Bardideh, M. \& Latifi, M.K(2004). Techniques and teaching methods. Tehran: Latifi.

Davidson, R. A.(2002). Relationship of study approach and exam performance. Journal of Accounting Education, 20, 29-44.

Fisher, M., King, J., \& Tague, G. (2001). Development of a Self Directed Learning Readness Scale for nursing education. Nurse Education Today, 21, 516-525.

Flavell, J. H. (1981). Cognitive monitoring. In W.P. Dickson (Ed.)Children's Oral Communication Skills (pp: 35-66). New York, $\mathrm{NJ}$ :Academic Press.

Gordanshekan, M(2011). Meta-cognition self-steering effect of teaching on student learning medical records University of Medical Sciences. Master's thesis.

Grow, G. (1991). Teaching learners to be self-directed: A stage approach. Adult-Education Quarterly, 41(3), 125-149.

Guliford .J.P. (1975).The nature of human intelligence. McGrahill. New York NY.invention Harpercollins publisher.

Jamalinejad, A (2013). Evaluate the effectiveness of metacognitive strategies on self-efficacy and academic achievement. Master's thesis, Azad University.

Kadivar, P (2008). Educational psychology. Tehran:Samt .

Kareshky, H.(2002). The impact on students' comprehension metacognitive strategies. Journal of Psychology. 21,1.

Linda .H.E \& Pinkleyey, Ch. (2006). Metacognitive strategies helpStudents to comprehend all text Reading improvement. Cholas Vista: 43 (1): $13-17$.

Martindale, C. (2007). Creativity, primordial cognition and personality. Personality and Individual Differences , 43: 1777-1785.

Musavi, S(2013). Effect of constructivism on creativity and academic achievement of students in fifth grade science class in the Mohr city. Master's thesis, Azad University.

Niazazary, K(2003). Metacognition in teaching-learning process. Tehran:Andishe.

Oliveira, A. L., \& Simoes, A. (2006). Impact of sociodemographic and psychological variables on the self directedness of higher education students. Sociodemographic and Psychology Variables in SDL, 1, 1-12

Pintrich, P. R. (1999). The role of motivation in promoting and sustaining self- regulatedlearning. International Journal of Educational Research, 31, 459-470.

Seif, A.A(2001). Educational psychology(Psychology of Learning and Teaching). Tehran: Agah.

Torrance ,E.P .(1979) . An instructional model for enhancing incubation. Journal ofCreative Behavior, 13(1): 23-35 